\title{
A Brief Discussion on the Application of Contrastive Analysis Theory in English Phonetics Teaching
}

Sha Li*

China West Normal University, Nanchong 6370002, Sichuan province, China. Email: 1838912205@qq.com

\begin{abstract}
Contrastive analysis is an important theory in second language acquisition, which aims to compare the similarities and differences between the learner's first language and the target language, so as to predict the difficulties in second language acquisition. Although the theory has its limitations, its role in second language acquisition is undeniable. Especially for English teachers, the transfer theory and Stimulus-Response-Reinforcement theory provide a lot of guidance for phonetics teaching.
\end{abstract}

Keywords: Contrastive Analysis; Transfer; Stimulus-Response-reinforcement; English Phonetics Teaching

\section{English phonetics teaching}

As the name suggests, contrastive analysis is also known as contrastive research. Its task is to carry out synchronic contrastive research on two or more languages, describe their similarities and differences, especially their differences, and apply this kind of research to other fields ${ }^{[1]}$. Linguists have found that most of the errors of foreign language learners are caused by the interference of the learner's mother tongue, namely, negative transfer. Therefore, they thought that if learners' mother tongue was compared with the target language, learners' possible difficulties could be predicted, that is, the possible negative transfer of learners could be predicted. In this way, targeted teaching can ultimately achieve the purpose of reducing learners' mistakes, which is the origin of comparative analysis. In foreign language teaching, contrastive analysis is not only an important research topic, but also an important research tool, so it has important research value.

English language skills include listening, speaking, reading and writing, among which listening and speaking are the first. The premise of listening is to master the correct pronunciation, which is based on the foundation of mastering English phonetic symbols. Phonics is the foundation of language learning and the most important part of foreign language teaching in the primary stage. Therefore, laying a good foundation of phonetics can help students make rapid progress in the cultivation of oral and listening comprehension ability. Oral and listening are relatively important links in students' language learning in middle and high stages, so phonetics teaching plays a decisive role. Speech is the means of expression and is the bridge that connecting the listening and speaking ability in communication. When learning English, we usually start with pronunciation first, then we can correctly spell according to the English phonetic symbols, and produce by "peaking". Therefore, phonetics teaching becomes one of the important elements of English language learning.

\section{Contrastive analysis}

This is an open-access article distributed under the terms of the Creative Commons Attribution Non-Commercial License (http://creativecommons.org/licenses/by-nc/4.0/), which permits unrestricted non-commercial use, distribution, and reproduction in any medium, provided the original work is properly cited. 
Contrastive analysis is an approach to the study of SLA which involves predicting and explaining learner problems based on a comparison of L1 and L2 to determine similarities and differences. It was heavily influenced by theories which were dominant in linguistics and psychology within the USA in the 1940s and 1950s, structuralism and behaviorism. The goal of CA was primarily pedagogical in nature: to increase efficiency in L2 teaching and testing.

One of the most important concerns in contrastive analysis theory is the transfer in language acquisition. In the case of SLA, this means that the transfer of elements acquired or habituated in L1 to the target L2. The transfer is called positive when the same structure is appropriate in both languages. The transfer is called negative when the L1 structure is used inappropriately in the L2. The assumption of transfer has a great influence on L2 teaching. Furthermore, following notions in behaviorist psychology, early proponents of CA assumed that language acquisition essentially involves habit formation in a process of Stimulus-Response-Reinforcement(S-R-R). Learners respond to the stimulus such as linguistic input, and reinforcement strengthens the response; they imitate and repeat the language that they hear, and when they are reinforced for that response, learning occurs.

In general, the author will focus on the above two points to illustrate their enlightenment to oral English teaching in the junior middle school.

\section{Language transfer}

Language transfer means that in the process of second language acquisition, learners transfer the language forms, rules and habits of their mother tongue to the second language acquisition when they use the second language. Most Chinese students are native speakers of Chinese and live in a Chinese environment, so when they learn English as a second language, they will be more or less influenced by their mother tongue. This also indicates that language transfer is inevitable in the process of 12 learners' transfer from their mother tongue to target language.

In the translation from Chinese to English, the Chinese phonetic alphabet has the greatest influence on phonetic symbols. There are 47 Chinese phonetic alphabets, including 23 initials and 24 finals. While in English, there are 48 phonetic symbols in English, including 20 vowels and 28 consonants. Even though there are great differences in pronunciation parts and other rules between Chinese phonetic alphabet and English phonetic alphabet, there are also great similarities. As for oral English teaching, as long as we make good use of the influence of positive transfer, we can better master English pronunciation skills, so as to improve the teaching ability.

In Chinese, there are initials and finals, and initials are similar to vowels in English while initials are similar to consonants in English ${ }^{[2]}$. On the surface, Chinese phonetic alphabet and English phonetic symbols are exactly the same in writing form, which means that Chinese phonetic alphabet provides great advantages in memory and writing. For example, Chinese phonetic alphabet has b, p, m, f, d, t, g, l, h, while English consonants have/b/, /p/,/m/, /f/, /d/, /t/, /g/, $/ 1 /, / \mathrm{h} /$. Therefore, in the spelling teaching of phonetic symbols, teachers can guide students to consciously combine Chinese phonetic alphabet with phonetic symbols when writing phonetic symbols, so as to improve the efficiency of memorizing phonetic symbols.

From the perspective of pronunciation, through comparative analysis, many initials in Chinese phonetic alphabet are similar to the vowels in English phonetic symbols, but some English phonetic symbols are longer in pronunciation and more exaggerated in mouth shape. In addition, many Chinese finials sound similar to English consonants, except that English consonants have no endings, while Chinese finials have heavy endings. Therefore, in vowel teaching, teachers can display Chinese initials which similar to vowel phonetic symbols, then give the general direction for vowel phonetic symbols, and finally conduct detailed pronunciation teaching. At the same time, when teaching consonants, the teacher can guide the students to learn the finials in their mother tongue, so that the correct pronunciation of English consonants can be obtained by removing each final sound. For example, the phonetic symbol/b/can be obtained by deleting (o) from b (bo), and the phonetic symbol/p/can be obtained by deleting (o) from p (po). In addition, there are nasalized sounds in Chinese phonetic alphabet, such as m, n, and in English the phonetic symbols /m/, /n/ is the same as in Chinese, both of which are bi-labial, with air flowing out through the nasal cavity. With the foundation of $\mathrm{m}$ and $\mathrm{n}$ in Chinese, it is easy to make correct sounds with only a little distortion for $/ \mathrm{m} / \mathrm{and} / \mathrm{n} / \mathrm{.}$. $\mathrm{n}$ the teaching of phonetic sym- 
bols, the teacher can first wake up the students' memory of Chinese phonetic alphabet, and show the relationship between it and phonetic symbols to them, leading to the general direction for phonetic symbols learning, and finally carry out the elaboration to explain the pronunciation rules of each phonetic symbol. Through the guidance of Chinese phonetic alphabet, teaching efficiency can be greatly improved, and students' confidence and interest in learning phonetic symbols can be enhanced at the same time.

In addition, the Chinese spelling rules is also of great help to English phonetic spelling. In Chinese phonetic alphabet, initials and finals can be spelled together to form a Chinese character, while in English, consonants and vowels are combined to form syllables, and several syllables are spelled together to form an English word. There are great similarities between the two. For example, the English word "box" is denoted by /boks/, in which b and x are consonants and $\mathrm{o}$ is vowels. By using the spelling rules related with Chinese phonetic alphabet, we can read $\mathrm{b}$ and o together, and the word "box" can be obtained. Therefore, in this aspect of teaching, teachers can guide students to associate English phonetic spelling rules with Chinese phonetic spelling rules, which can ease the boring teaching of phonetic spelling, make the classroom atmosphere become active, and enhance students' interest in learning.

To sum up, it is advisable for using Chinese phonetic alphabet to assist the teaching of English phonetic symbols. Therefore, in the future of teaching of English phonetic symbols, teachers should first affirm the promoting effect of Chinese phonetic alphabet and make full use of effective resources to make use of students' existing Chinese phonetic foundation to assist English phonetic symbols learning. Secondly, it is necessary to cultivate students' awareness of Chinese phonetic symbols and English phonetic symbols. Teachers should think actively to help students to establish the internal relationship between Chinese phonetic alphabet and English phonetic symbol, and use the positive transfer of language to improve students' learning efficiency of English phonetic symbol; Thirdly, teachers should correctly guide students to form a complete phonetic system. To make students learn the phonetic symbol, the first teachers in teaching should set up the correct phonetic teaching concept, and under the guidance of the theory knowledge, innovation teaching methods to help students establish the platform and the connection between the two languages, and excavate students' potential. In short, there are differences and similarities between Chinese pronunciation and English pronunciation. For English learners, it is necessary to overcome the influence and interference and take advantage of the positive factors of native language transfer, so as to make English pronunciation learning easier and better. At the same time, teachers should make reasonable use of the relationship between mother tongue and English learning to help English learners improve their learning efficiency by using the positive transfer of mother tongue, so as to make the English learning process simpler and more efficient.

\section{Stimulus-Response-Reinforcement(S-R-R)}

"Stimulus-Response-Reinforcement" is often seen as the basis of behaviorism. From the idea, through conditioned reflexes, people can make connections between stimuli and responses. The inspiration of this view for language teaching is that children's language acquisition is the appropriate response to the surrounding environment or adult's words ${ }^{[3]}$. If the response is correct, adults will give the corresponding material or oral encouragement and reinforcement, thus forming the language habit. This part will explain the enlightenment of the theory to English phonetics teaching from the following aspects.

Firstly, practice makes perfect. In phonetics teaching, teachers must ask students to practice as children learn their mother tongue. In this theory, practice is the main way for learners to make appropriate responses to "stimulus" and is also an important way to master the target language. Only language practice can realize the "response" to the "stimulus". In phonics teaching, only through continuous practice of pronunciation can progress be made, and teachers can test students' learning effect and master their learning situation through students' output.

Secondly, imitation plays an important role in language learning. In the process of foreign language learning, imitation is often regarded as the basis for learners to make appropriate responses and the first step to form language habits. In the teaching of phonetic symbols, teachers can provide students with relevant pronunciation videos. Of course, it is best if teachers can do demonstrations in person. Students can get intuitive learning experience by imitating the pro- 
nunciation and mouth shape of teachers or videos. At the same time, teachers can encourage students to watch more English videos, such as TED or some movies, and guide students to choose their favorite British or American sounds, and then imitate the pronunciation of characters in the movies, so as to improve their oral English and reduce the occurrences of Chinglish.

Thirdly, the principle of reward is very important in this theory. In the process of foreign language learning and teaching, learners should be constantly encouraged and rewarded by teachers, and the forms of encouragement and reward are diversified, including oral encouragement and achievement reward. Timely and appropriate encouragement and rewards are conducive to enhancing learners' confidence in language learning and enhancing their interest in language learning. Therefore, in phonetics teaching, if students have correct pronunciation or make progress, teachers should give them oral or achievement rewards in a timely manner, so as to enhance students' confidence and strengthen the teaching effect. However, it should be noted that rewards should not be too materialized. Material rewards are easy to change students' original learning intention and promote the formation of unhealthy and competitive atmosphere.

The above briefly introduces the main principles of this theory and its beneficial effects on foreign language teaching. Admittedly, this theory also has its own shortcomings. For example, this theory overemphasizes the role of external conditions on internal factors in language acquisition, and fails to fully explain the complex phenomena related to children in the process of language acquisition. However, if the Stimulus-Response-Reinforcement theory is objectively analyzed from the perspective of foreign language teaching, it is still of practical significance, because it explores the internal factors of foreign language learning and the correlation between teaching and learning, which is conducive to teachers to guide their teaching practice.

\section{Conclusion}

Contrastive analysis theory has made an indelible contribution to foreign language teaching. It puts forward a set of scientific contrastive analysis procedures, discovers a lot of special linguistic phenomena, enriches linguistic theory. Based on the transfer and reinforcement theory in the contrastive analysis theory, this paper puts forward some suggestions for English phonetics teaching, hoping to provide some help for the reform and improvement of English phonetics teaching in the future.

\section{References}

1. Ai C. The Research Value of Contrastive Analysis and Error Analysis in Foreign Language Teaching (in Chinese). Journal of Sichuan Normal University (Social Sciences Edition) 2007; (03): 113 - 117.

2. Yu J, Ying Y, Shuang X. On the influence of positive transfer of mother tongue on English learners (in Chinese). Nei Jiang Science and Technology 2020; 41(08): 99 - 101.

3. Li L, Yi X. S-R Theory and Its Influence on Foreign Language Teaching (in Chinese). Foreign Language Teaching 2002; (02): $75-77$. 